Revista de Antropología Social

ISSN: 1131-558X

http://dx.doi.org/10.5209/RASO.56047

\title{
Ortega ante la antropología cultural
}

Ricardo Sanmartín Arce ${ }^{1}$

ORTEGA Y GASSET, José, 2015. Las Atlántidas y otros textos antropológicos. Edición de José Ramón Carriazo Ruiz. Madrid: Editorial Tecnos.

El libro que comentamos se nos presenta como una aproximación posible a un clásico de nuestra filosofía, con la intención de despertar nuevas vocaciones. Ortega tuvo una clara preocupación a lo largo de su vida por las innovaciones metodológicas que la Antropología Cultural aportaba al conjunto de las ciencias sociales. Este libro, en realidad, es una recopilación de textos de Ortega que tuvieron en su tiempo una fácil adscripción al campo de la Antropología Social por su referencia a etnólogos como Frobenius, al Difusionismo, a las culturas africanas, al estudio filosófico de la guerra y, sobre todo, a aquella constante preocupación orteguiana de modernizar la metodología de las ciencias sociales desde principios del siglo XX, para lo cual Ortega enraizó su explicación de la obra de W. Dilthey en la crítica a la Escuela Histórica Alemana.

A esa recopilación, suma su editor una Introducción con una amplia, aunque incompleta, bibliografía. En dicha Introducción, al presentar sus criterios editoriales, se percibe con claridad el deseo de ofrecer una edición que compare las distintas versiones de los textos recopilados. Ortega, no lo olvidemos, escribió en la primera mitad del siglo XX, con un excelente castellano - algo pomposo en sus conferencias, reconocería años después H.G. Gadamer- pero en una época en la que no existía red informática y toda publicación era en papel. El profesor Carriazo trabaja en este libro más como lingüista que como antropólogo y, desde dicha perspectiva, se preocupa por el seguimiento de pequeñas variaciones según el texto aparecía primero en la prensa, luego como artículo o, finalmente, en sus Obras Completas. Como antropólogo, carezco de competencia para estimar en su justo valor el trabajo historiográfico y filológico y, en consecuencia, me abstendré de comentarlo. Como mero lector, estimo que a veces puede cansar la repetición de textos y notas a pie de página, pues acaban desviando la atención de aquello que debiera ocuparla, esto es, de los problemas e ideas con las que Ortega pretende resolver las preguntas que la época y la innovación científica le planteaba. Mi comentario, inevitablemente, se orientará desde la Antropología Cultural, no tanto sobre el propio Ortega, pues ya lo hice en 1998 en la Reis ${ }^{2}$, sino sobre la selección que ahora nos ocupa. Solo

\footnotetext{
Universidad Complutense de Madrid (UCM) rsanmart@cps.ucm.es

2 Sanmartín Arce, R., 1998: "En torno a Ortega y la gente". Revista Española de Investigaciones Sociológicas, $\mathrm{n}^{\circ}$ 82, Abril-Junio, pp. 73-96. Seleccionado por el CIS y publicado en REIS English Edition, año 1999, pp.41 a 64. Incluido en R.Sanmartín, 1999: Valores culturales. El cambio social entre la tradición y la modernidad. Editorial COMARES, Granada.
} 
quisiera antes matizar la afirmación del editor sobre la escasa huella de Ortega en la literatura científica etnológica española. Esos errores pueden suceder al cruzarse dos comunidades científicas diferentes - lingüística y antropológica- sobre un mismo autor, Ortega en este caso, pues en realidad ya en el primer libro que publicó Carmelo Lisón Tolosana en Oxford, en 1966, constan ocho citas sobre Ortega y, en su primer libro sobre Antropología Social en España, de 1971, hay otras ocho referencias a Ortega. Además de la correspondencia entre Ortega y Julio Caro Baroja - que hemos citado todos al estudiar a Ortega - es indudable la influencia de Ortega en Julio Caro Baroja, quien, además, cita artículos y obras de Ortega en varios de sus libros (en 1974, 1985, etc.) De hecho, las obras de Ortega son ampliamente citadas en distintas asignaturas de los planes de estudio actuales, Grado y Master, al menos en la Universidad Complutense.

J.R. Carriazo recoge, como indica en su estudio introductorio, lo que él considera como principales aportaciones de D. José Ortega y Gasset en su calidad de divulgador o investigador en temas antropológicos, así como introductor de Leo Frobenius. Sin embargo, la influencia de Ortega en la Antropología va mucho más allá de ello, y no puede apreciarse bien confiando en los títulos de aquellos textos que expresamente nombran la Antropología o presentan datos etnográficos de distintas culturas. Ortega, ni era ni pretendió ser un antropólogo. Como realmente influyó fue con sus propuestas metodológicas ante los fenómenos sociales y culturales que fue presentando en los libros que publicó como filósofo, aun cuando en los títulos de los mismos (siempre bastante desorientadores en Ortega) no se mencionasen los términos "etnología", "antropología" o "cultura". Su libro Ideas y creencias no es un libro de antropología de la religión, como tampoco su libro En torno a Galileo lo es sobre física. El tema de nuestro tiempo no es un libro sobre periodismo ni sobre historia contemporánea, y así sucesivamente, y, sin embargo, son obras decisivas, incluido su famoso prólogo para alemanes, para fundar correctamente el método y la teorización de las ciencias sociales, incluida la Antropología Social. Es por esa vía como Ortega aportó un pensamiento realmente fértil y mucho más moderno que las viejas ideas de Bachofen, Frobenius, Schulten, Bastian o Ratzel.

Carriazo destaca bien el cambio que Frobenius supuso al reorientar la atención de la comunidad científica hacia la historia y la geografía, pues eso contribuyó a dotar de mayor rigor y empirismo a las antiguas reconstrucciones de los evolucionistas. Son, sin duda, sabias las palabras de Ortega con las que describe la aportación que él ha percibido gracias a la Antropología, pues cuando contemplamos las diferencias culturales "es como una nueva distancia ante lo histórico [...] Aplicar el punto de vista etnológico a los pueblos cultos equivale, pues, a distanciarse de estos, a empujarlos lejos de nuestra proximidad desentendiéndose de presuntas comunidades"3. Ortega entendió perfectamente las claves técnicas de la comparación y del contacto convivencial con la vida cultural en cualquier contexto: "Tenemos que distanciarnos del prójimo para hacernos cargo de que no es como nosotros; pero a la vez necesitamos acercarnos a él para descubrir que, no obstante, es un hombre como nosotros, que su vida emana sentido"4. Gracias a la comparación antropológica, entendía Ortega, la historia ya no es algo meramente occidental, ya no cabe tamaño etnocentrismo, pues la Antropología globalizó la historia.

Citado por Carriazo en p. 42.

Ibid. p. 43. 
Sin duda, seguirán siendo sus intereses filosóficos los que empujen la atención de Ortega hacia los nuevos logros de la Antropología, pero eso no hace sino ayudar a que la propia Antropología se dote de mayor hondura. Aquella preocupación sobre la Antropología Filosófica que "nos enseñará que las almas tienen formas diferentes, lo mismo que los cuerpos", ya está llevando hoy en día al estudio antropológico de "la estructura de la intimidad humana"s. Ortega sugiere la necesidad "de reconstruir la estructura radicalmente diferente que ha tenido la conciencia humana [...] Es preciso ahondar más y advertir que no solo los contenidos de su espíritu se diferencian de los nuestros, sino que el aparato mismo espiritual es muy otro $[\ldots]$ hace falta ir hasta el fondo y reconocer que las categorías de la mente humana no han sido siempre las mismas" 6 , pues las "diferencias de configuración de la persona interna [...] inducen a construir una anatomía psicológica" . Se trataría de estudiar "profundidades de la persona mucho más radicales que el plano de su voluntad"8.

Son muchas las categorías que Ortega sugiere como instrumento para la investigación en Antropología cultural, muchas de ellas más tarde presentes también en Gadamer ${ }^{9}$, en Koselleck ${ }^{10}$, en Ricoeur ${ }^{11}$ : "Pocas peripecias más graves pueden acontecer en el seno de una civilización que una mudanza de su horizonte. Esta línea lejana, y, en apariencia, inerte, que circunscribe la existencia del hombre, es uno de los máximos agentes del proceso histórico. Por eso conviene formarse de él una idea más exacta, y [...] ver en él un órgano vivo que colabora activamente en los destinos del hombre" ${ }^{\prime 2}$. El enfoque holístico, la idea de horizonte, la integridad de la persona - que tomará de Dilthey- como ser no meramente cognitivo, no meramente racional, sino que quiere, siente y representa; la noción de suelo histórico, de época o de generación, la del nivel del destino; la necesidad de repensar el sujeto de la historia, la verdadera unidad de análisis en cada nivel de comparación e investigación en las ciencias sociales; entender que mientras "el fenómeno físico está constituido por materia, el fenómeno histórico está formado por sentido"13 que "los fenómenos vitales comienzan donde los fenómenos mecánicos concluyen"14; que hay que educar favoreciendo la creatividad del niño... y tantas otras ideas, alguna, incluso, compartida con Jung sobre los estratos más profundos de la subjetividad que "forman el subsuelo mental desde el cual iniciamos nuestra propia obra de conocimiento [...] constituido por la herencia de lo colectivo histórico" ${ }^{15}$, todas ellas son, sin duda, aportaciones que modernizaron muchas de nuestras ciencias sociales. Como indicaba en mi citado artículo, si la comunidad científica de la Antropología hubiese leído a Ortega habría adelantado en, al menos, 35 años el nacimiento de lo que difundió C. Geertz como Antropología Interpretativa.

Leamos, pues, a Ortega.

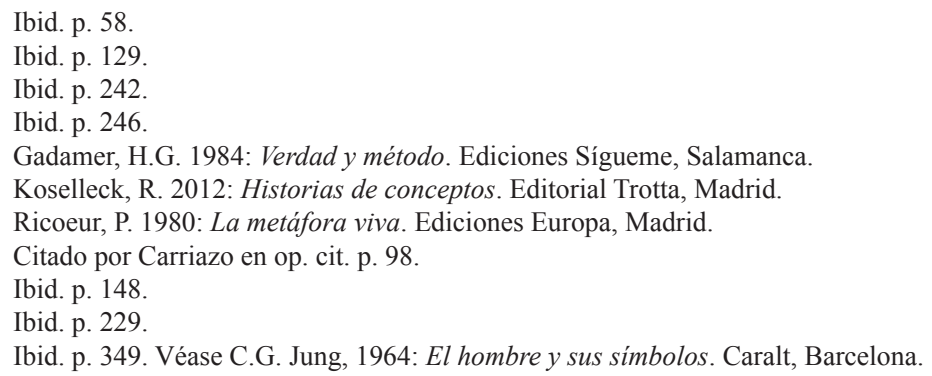

